\title{
Characterization of Renewable PUF and Preparation of Polyurethane Foam Composites with Alkali Lignin/Renewable PUF
}

\author{
Changyu $\mathrm{Li}^{*}{ }^{1} \mathrm{Lili} \mathrm{Liu}^{2}$ and Chuanyun $\mathrm{Zhu}^{2}$ \\ ${ }^{I}$ Key Laboratory of Bio-based Material Science and Technology, Ministry of Education, Northeast Forestry University, \\ Harbin, 150040, P. R. China \\ ${ }^{2}$ Heilongjiang Institute of Technology, Harbin 150001, P.R. China
}

\begin{abstract}
The renewable PUF was prepared by the alcoholysis of the used polyurethane foam composite and the polyurethane foam composite was also prepared by alkali lignin and renewable PUF. The renewable PUF was examined by GC-MS, the results showed the renewable PUF mainly consists of glycol, propanol and 1, 2-Benzenedicarboxylic acid, which can directly be used as the raw material of polyurethane foam composite. The dose of glycol impacts on the performances of renewable PUF, the viscosity of renewable PUF decreased with the increase of the dose glycol. The prepared polyurethane foam composite was also tested. Thermal stability as well as compression property was studied. It was obtained from the TG curve and the DTG curve that the initial decomposition temperatures of polyurethane foam composites with $10 \%$ renewable PUF and without renewable PUF were $286.75^{\circ} \mathrm{C}$ and $300.63{ }^{\circ} \mathrm{C}$, respectively, which showed the renewable PUF affected the thermal stability of the polyurethane foam composite. The compressive strength $(\sigma 10)$ was from $203 \mathrm{kPa}$ to $125 \mathrm{kPa}$, which were affected by the dose of renewable PUF.
\end{abstract}

Keywords: Alkali lignin, renewable PUF, polyurethane foam, compression properties.

\section{INTRODUCTION}

One of the major priorities of 21 st century is the replacement of fossil carbon source by a renewable raw material (biomass). Nowadays, the world is strongly committed with sustainable development and terms such as bioproducts, bioenergy, bioeconomy being used frequently by politicians and investors [1]. Lignin, a complex and heterogeneous aromatic biopolymer in woody and herbaceous plants, is one of the most abundant natural polymers on earth, comprising $20-30 \%$ of most woods and 5$15 \%$ of most agricultural crop residues [2]. Most of them are directly burned without any disposal, which pollutes the environment and wastes the biomass resource. The waste plastics has become a major source of environmental pollution with the development of Chinese plastics industry and the increasingly widespread use of plastic products, polyurethane foam composite is an important material which is widely used in construction industry, energy saving building and floating field, the used polyurethane foam composite has been one of major source of environmental pollution, a few literatures have reported that the used polyurethane foam composite were decomposed, however, the analysis of RPUF has not been reported, which is important to reuse RPUF. Above all, it is important to use the lignin and waste plastics effectively [3]. The lignin or waste plastics was used in a few literatures [4-6], however, to the best of our knowledge, the lignin and waste plastics

*Address correspondence to this author at the Key Laboratory of Bio-based Material Science and Technology, Ministry of Education, Northeast Forestry University, Harbin, 150040, P.R. China; Tel: +86-0451-82191740; Fax: +86-0451-82191740;

E-mails: lichangyu10@126.com, lichangyu10@163.com used together were not reported. In this study, the used polyurethane foam composite was decomposed using glycol as alcoholysis and polyurethane foam composites were prepared using alkali lignin and RPUF as raw materials and the effect of the dose of RPUF on the performance of polyurethane foam composites also were studied.

\section{EXPERIMENT}

\subsection{Preparation of Polyurethane Foam Composites}

RPUF was prepared according to literature [7]. The polyether polyol, RPUF, catalysts, foaming agents, foam stabilizers and alkali lignin (Alkali lignin ratio is fixed $0.5 \%$ of the total mass) were mixed according to certain radio, then the solution was mixed with the diphenylmethane diisocyanate (MDI), and quickly poured into the mold. The polyurethane foam composites can be prepared after the solution was cured.

\subsection{Characterization}

RPUF was examined by using GC/MS (N6890/5975B, Agilent) equipped with a HP-5MS capillary column of $30 \mathrm{~m}-$ $50 \mathrm{~mm}-0.25 \mathrm{~mm}$ film thickness. Helium was employed as the carrier gas. All the measurements were carried out in fullscan mode, with a mass range of $50-450 \mathrm{~m} / \mathrm{z}$. The injected volume was $1.0 \mathrm{~mL}$ in the splitless mode. The temperature program was initiated at $60{ }^{\circ} \mathrm{C}$ to the final temperature $260^{\circ} \mathrm{C}$, heating rate of $5{ }^{\circ} \mathrm{C} / \mathrm{min}$. The injector temperature was $220^{\circ} \mathrm{C}$ in all analyses. Dentification of compounds was achieved by comparing the retention times with those of authentic compounds and the spectral data obtained from the Wiley and NIST libraries. The viscosity coefficients of RPUF were examined by using rotary viscosimeter (NDJ-7) 
and the hydroxyl values of RPUF were calculated according to the method of the literature [8].

The thermal conductivities of the polyurethane foam composites were tested, using the tc-2/a heat conduction coefficient detector; The compressive strengths were determined by Zwick/z010 universal testing machine, which were pressed by $2 \mathrm{~mm} / \mathrm{min}$; The thermal stabilities were investigated by using PYRIS 6 TGA thermogravimetry analysis under the conditions of nitrogen atmosphere and heating rate of $5{ }^{\circ} \mathrm{C} / \mathrm{min}$. The microstructures were determined using an environmental scanning electron microscope (QUATA200) (SEM).

\section{RESULTS AND DISCUSSION}

The used polyurethane foam composite (the mass is $0.04 \mathrm{~kg}$ ) were decomposed using different dose glycol. As listed in Table 1, the hydroxyl value of the products increased with the increase of glycol dose while the viscosity coefficient of the products decreased. The product prepared with the $40 \mathrm{~mL}$ of glycol as solution was examined by GC/MS (Fig. 1), the results showed the product had many composites. These composites were mainly glycol, propanol, 1, 2-Benzenedicarboxylic acid, and so on, which can directly be used to prepare new polyurethane foam composite.

Table 1. The Impact of Glycol Dose

\begin{tabular}{|c|c|c|}
\hline Glycol Dose/mL & Viscosity Coefficient/mPa·s & Hydroxyl Value \\
\hline \hline 20 & 47000 & 777.84 \\
25 & 22000 & 811.24 \\
30 & 19000 & 848.55 \\
40 & 17000 & 988.80 \\
\hline
\end{tabular}

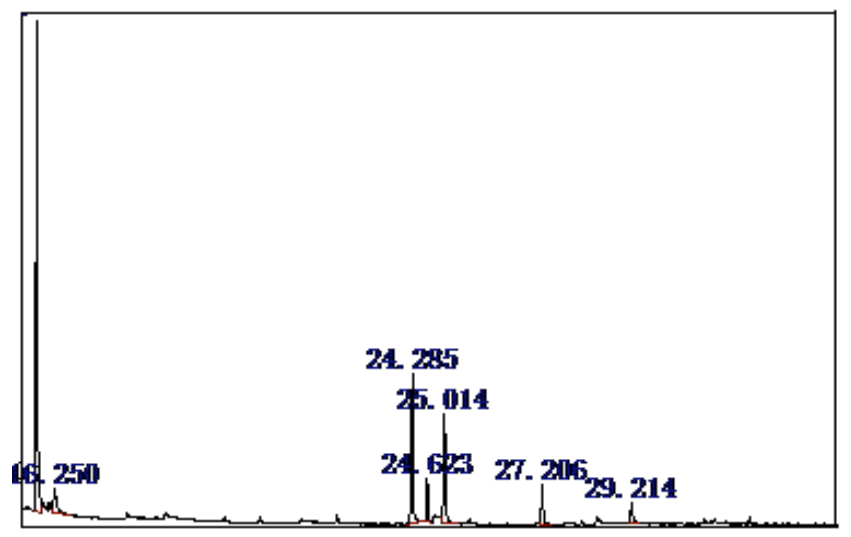

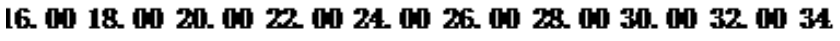

\section{Time ( $\mathrm{min})$}

Fig. (1). GCs pectrum of product from RPUF.

The thermal conductivities of polyurethane foam composites with different RPUF are between 0.0249 to 0.034 $\mathrm{W} /\left(\mathrm{m} \cdot{ }^{\circ} \mathrm{C}\right.$ ) (shown in Table 2 ), which are very close to the values of the china national standard building insulation standards of rigid polyurethane foams(0.022-0.027 $\left.\mathrm{W} /\left(\mathrm{m} \cdot{ }^{\circ} \mathrm{C}\right)\right)$, however, Lignin and RPUF could lower cost and realize the recycling use of the waste material and the biological degradation. The thermal conductivity increased and insulation performance decreased with the increase of
RPUF, we proposed the thin film of the cell became thinner with the increase of RPUF so that the open porosity of the products increased, which decreased the insulation performance of the products.

Table 2. The Thermal Conductivities of Polyurethane Foam Composites with Different Renewable PUF

\begin{tabular}{|l|c|c|c|c|}
\hline The Dose of the Renewable PUF & $\mathbf{0 \%}$ & $\mathbf{5 \%}$ & $\mathbf{1 0} \%$ & $\mathbf{1 2 \%}$ \\
\hline \hline thermal conductivity ( W/(m/k) ) & 0.0249 & 0.0278 & 0.0302 & 0.034 \\
\hline
\end{tabular}

Fig. (2) is compression curves of the products with or without RPUF. According to the Fig. (2), all the curves are similar and all the curves are linear when the deformation of the products is less than $10 \%$. Table 3 shows the compression $\sigma_{10}$ of polyurethane foam composites with Alkali Lignin/ Renewable PUF. The compression $\sigma_{10}$ of polyurethane foam composites with the different dose of RPUF are between 203 to $125 \mathrm{kPa}$ (shown in Table 3), which are higher than the values of the china national standard building insulation standards of rigid polyurethane foams $(100 \mathrm{kPa})$, so they can take place of the traditional insulation material. According to Table 3, the compression performance of the products nearly decreased with the increase of RPUF, we consider the lignin and RPUF affect the microstructures of products and the microstructure has a great effect on the compression performance [7].

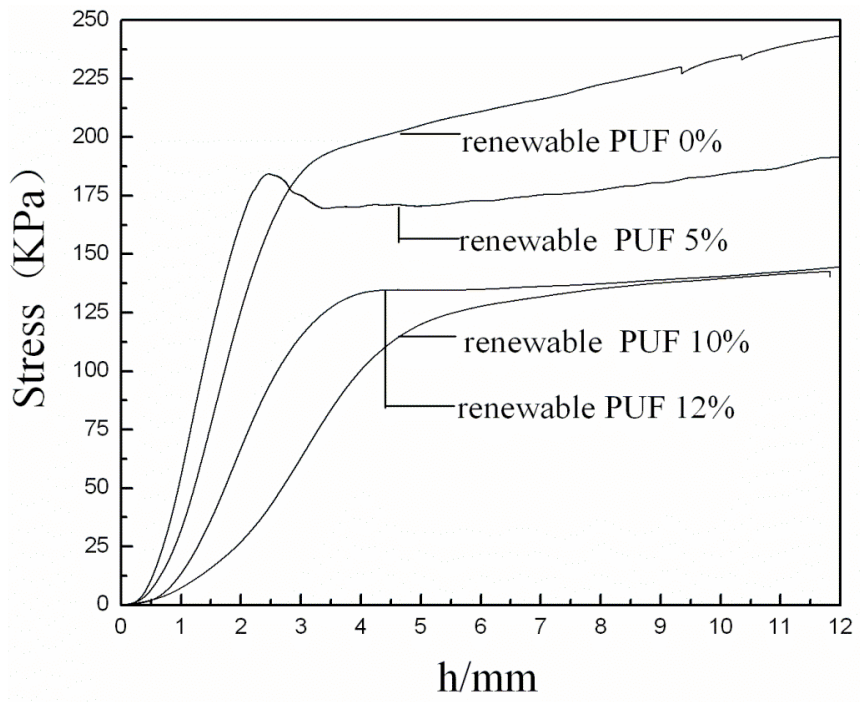

Fig. (2). The compression curves of polyurethane foam composites with different renewable PUF.

Table 3. The $\sigma_{10}$ of Polyurethane Foam Composites with Different Renewable PUF

\begin{tabular}{|c|c|c|c|c|}
\hline The Dose of the Renewable PUF & $\mathbf{0 \%}$ & $\mathbf{5 \%}$ & $\mathbf{1 0 \%}$ & $\mathbf{1 2 \%}$ \\
\hline \hline$\sigma_{10} / \mathrm{kPa}$ & 203 & 171 & 125 & 135 \\
\hline
\end{tabular}

Fig. (3) is the TG-DTG curves of the products with or without RPUF, tested under the conditions of nitrogen atmosphere. Fig. (3a) is the TG-DTG curve of the product without RPUF, which shows the product began thermal decomposition at $300.63^{\circ} \mathrm{C}$ while the product with the dose 
(a) without renewable PUF

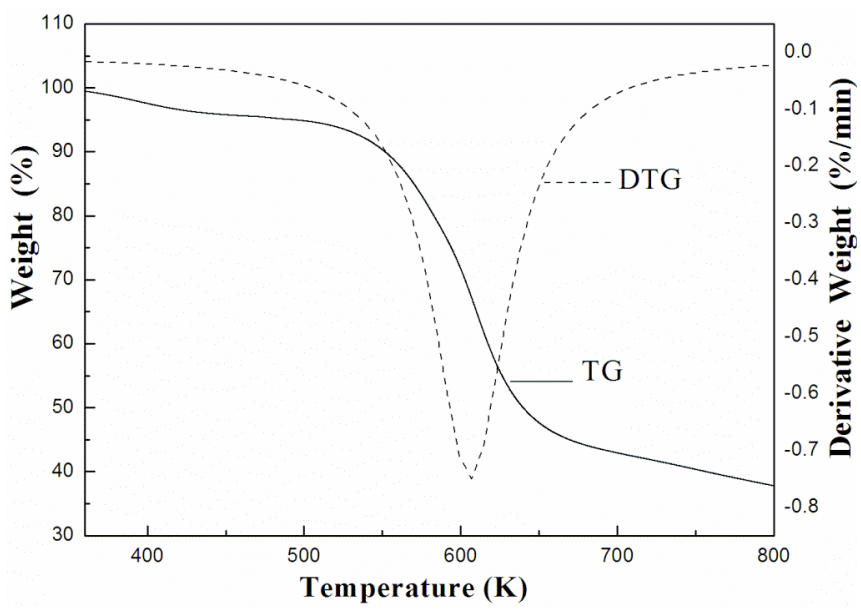

(b) with the dose of renewable PUF to $10 \%$

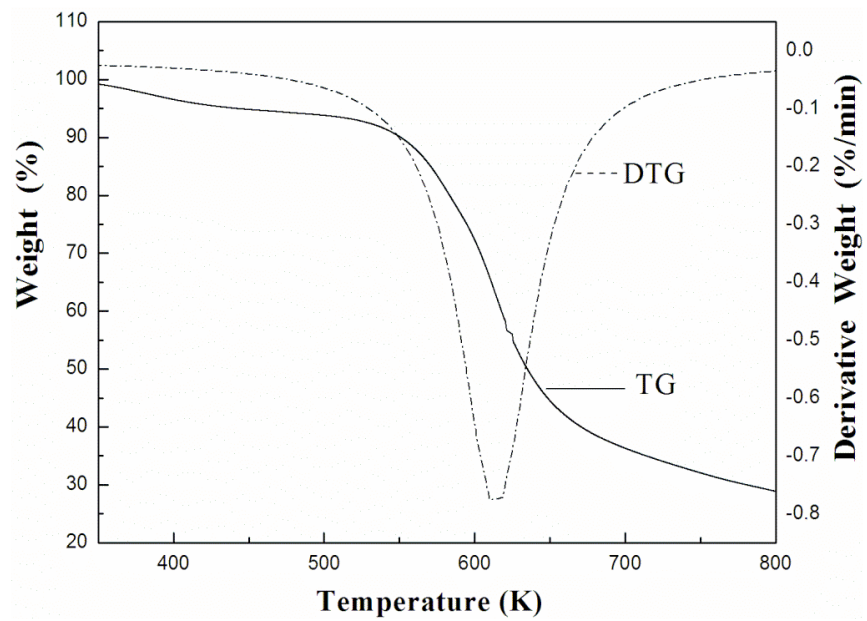

Fig. (3). TG-DTG curves of the products with or without renewable PUF.

of RPUF to $10 \%$ began thermal decomposition at $286.75^{\circ} \mathrm{C}$, which shows RPUF affects the thermal stability of the products. The possible reason is RPUF obtained by decomposing rigid polyurethane foam is oligomers while oligomers began thermal decomposition at lower temperature.

Fig. (4) shows the SEM micrographs of the products with or without RPUF, which shows the products consist of many cells like football that is composed of skeleton and thin film. Lignin existed in the skeleton $[9,10]$ so that the compression performance increased. The dose of RPUF has a great effect on the structure of cells. The thick of the skeleton decrease

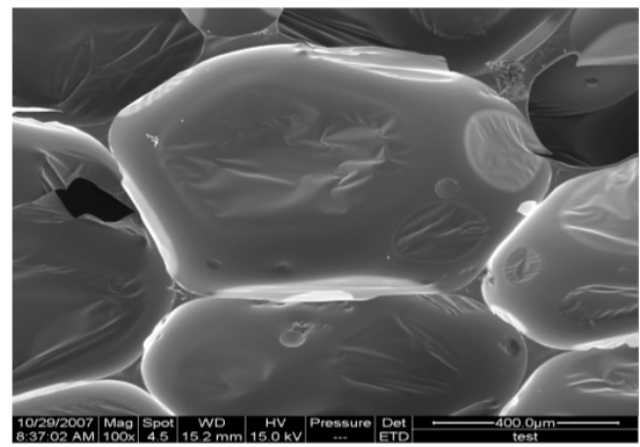

(a) without renewable PUF

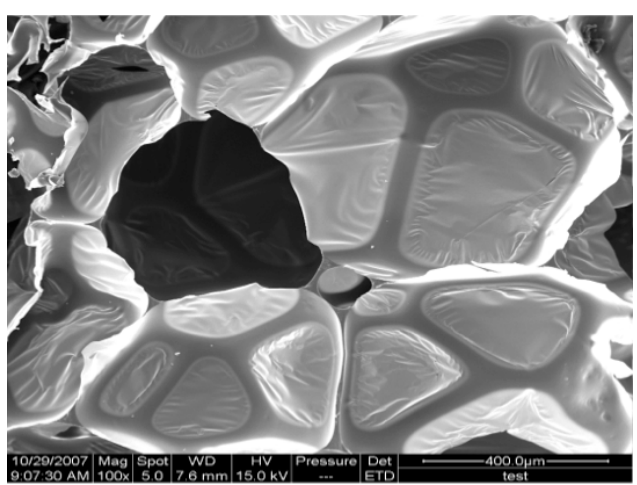

(c) the dose of renewable PUF to $10 \%$ with the increase of RPUF and the open porosity of cells also increase, which prove the result of the thermal conductivity.

\section{CONCLUSIONS}

The polyurethane foam composite was prepared by alkali lignin and RPUF that was prepared by the alcoholysis of the used polyurethane foam composite. Alkali lignin and RPUF have a great effect on the thermal performance and compression performance. The thermal performance and compression performance decreases with the increase of the dose of RPUF because the dose of RPUF affects the microstructures of the products

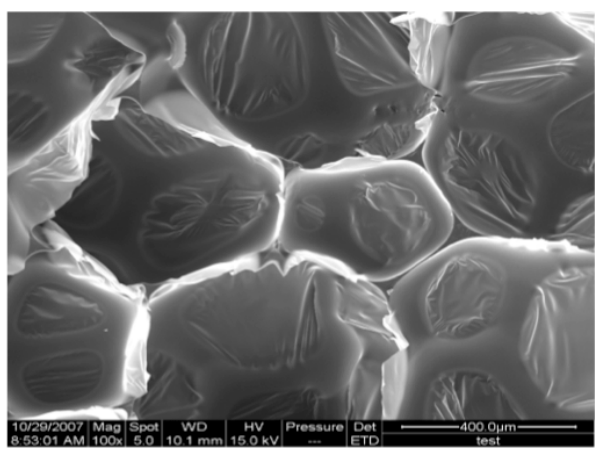

(b) the dose of renewable PUF to 5\%

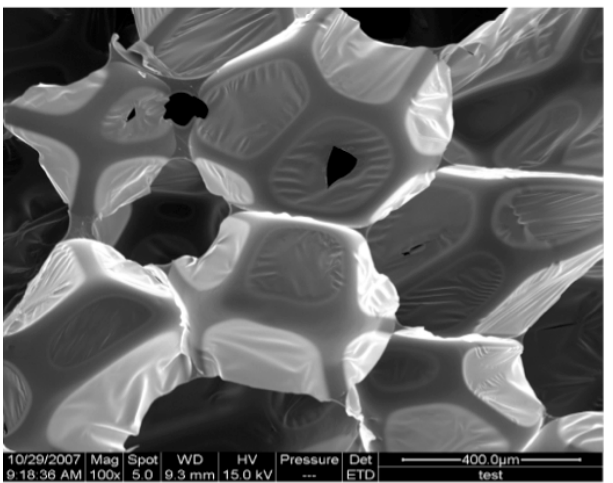

(d) the dose of renewable PUF to $12 \%$

Fig. (4). SEM micrographs of the products with or without renewable PUF. 


\section{ACKNOWLEDGEMENTS}

This study was funded by the Fundamental Research Funds for the Central Universities DL09BB45.

\section{REFERENCES}

[1] Nakamura Y, Sungusia MG, Sawada T, Kuwahara M. Lignindegrading enzyme production by Bjerkandera adusta immobilized on polyurethane foam. J Biosci Bioeng 1999; 88: 41-7.

[2] Borges da Silva EA, Zabkova M, Araújo JD, et al. An integrated process to produce vanillin and lignin-based polyurethanes from Kraft lignin. Chem Eng Res Des 2009; 87: 1276-92.

[3] Li CY, Liu LL, Zhang HY, Yan B, Zhu CY. The preparation method of the rigid fluorine-free polyurethane foam insulation materials with lignin and used polyurethane foam powder as the raw materials. CN101012332, August 8, 2007.

[4] Wang H, Chen HZ. A novel method of utilizing the biomass resource: Rapid liquefaction of wheat straw and preparation of biodegradable polyurethane foam (PUF). J Chin Inst Chem Eng 2007; 38: 95-102.

[5] Hatakeyema H, Tanamachi N, Matsumura H, Hirose S, Hatakeyama T. Bio-based polyurethane composite foams with inorganic fillers studied by thermogravimetry. Thermochim Acta 2005; 431: 155-60.

[6] Liu YT, Zhang JX, Yin DW, Lv B. Research progress of recycle of waste plastics for new materials. J New Chem Mater 2009; 37: 3-5.

[7] Liu LL, Li CY. Preparation and Cell Body Structure Property of Reticulated Polyurethane Foam Composites from Ligninsulfonate/ Renewable Polyurethane Foam. Chem Ind Forest Prod 2010; 30: 47-51.

[8] Polyether polyols-Determination of acid number, GB 12008.5-89

[9] Xie YM, Gu RJ, Wu H. Technology of polyurethane-reinforcement of paper. Paper Chem 2000; (3): 1-3.

[10] Tao YZ, Guan YT. Study of chemical composition of lignin and its application. J Cell Chem Technol 2003; 11: 42-55.

(C) Li et al.; Licensee Bentham Open.

This is an open access article licensed under the terms of the Creative Commons Attribution Non-Commercial License (http://creativecommons.org/licenses/ by$\mathrm{nc} / 3.0 /$ ) which permits unrestricted, non-commercial use, distribution and reproduction in any medium, provided the work is properly cited. 